\title{
Prevalence of hypertension and its association with stress, Indian diabetes risk score and obesity in rural population of Meerut
} Manish Garg ${ }^{1}$, Rahul Bansal ${ }^{2}$, Monika Gupta ${ }^{3}$, Chhavi Kiran Gupta ${ }^{4}$

${ }^{1}$ Assistant Professor, Department of Community Medicine, Rama Medical College, Hapur, Uttar Pradesh; ${ }^{2}$ Professor \& Head, Department of Community Medicine, Subharti Medical College, Meerut, Uttar Pradesh; ${ }^{3}$ Associate Professor, Department of Community Medicine, Subharti Medical College, Meerut, Uttar Pradesh; ${ }^{4}$ Assistant Professor, Department of Community Medicine, Subharti Medical College, Meerut, Uttar Pradesh

\begin{tabular}{|c|c|c|c|c|c|c|c|c|}
\hline Abstract & Introduction & Methodology & Results & Conclusion & References & Citation & \multicolumn{2}{|c|}{ Tables / Figures } \\
\hline \multicolumn{9}{|c|}{ Corresponding Author } \\
\hline \multicolumn{8}{|c|}{$\begin{array}{l}\text { Dr Monika Gupta, Associate Professor, Department of Community Medicine, Subharti Medical College, } \\
\text { Meerut, Uttar Pradesh } \\
\text { E Mail ID: } \underline{\text { dr monikagupta81@yahoo.co.in }}\end{array}$} & 回语回 \\
\hline
\end{tabular}

\section{Citation}

Garg M, Bansal R, Gupta M, Gupta CK. Prevalence of hypertension and its association with stress, Indian diabetes risk score and obesity in rural population of Meerut. Indian J Comm Health. 2020;32(1):62-66.

Source of Funding: Nil Conflict of Interest: None declared

\section{Article Cycle}

Received: 20/11/2019; Revision: 05/01/2020; Accepted: 02/03/2020; Published: 31/03/2020

This work is licensed under a Creative Commons Attribution 4.0 International License.

\section{Abstract}

Background: The prevalence pattern of hypertension in developing countries is different from that in the developed countries. In India, community surveys have documented that between three and six decades, prevalence of hypertension has increased by about 30 times among urban dwellers and by about 10 times among the rural inhabitants. Many studies on hypertension are available from urban areas but there are less studies among the rural population. Aim \& objectives: To determine the prevalence \& corelates of hypertension among the adults in rural population of Meerut. Settings and Design: community based cross-sectional study conducted in rural Meerut. Materials and Methods: 150 participants were selected by systematic random sampling. Data was collected using a pre designed, structured schedule, including blood pressure and anthropometric measurement of participants. Results: The prevalence of hypertension came out to be $33.3 \%$. In rural population high Indian Diabetes Risk Score (IDRS), higher Body Mass Index (BMI), increased Waist Hip Ratio (WHR), Truncal obesity and disturbed sleep were significantly associated with hypertension, Conclusions: a high prevalence of hypertension was seen in this rural area which requires intervention at primary health care level for its prevention.

\section{Keywords}

Hypertension; Rural; BMI; Truncal obesity

\section{Introduction}

WHO defines hypertension as 'a condition in which the blood vessels have persistently raised pressure, putting them under increased stress. (1) An epidemiological shift in the prevalence of hypertension in developing countries as compared to the developed countries has been observed. $(2,3)$ Studies from India and Bangladesh have shown upward trend in the prevalence of hypertension.(4)

As hypertension is a direct risk factor for many cardiovascular diseases so it is important to know about its prevalence and risk factors in a community. India in particular has seen an increasing trend of hypertension since last few decades and this increase has been evident in urban as well as rural populations of India. Community survey in India have documented that between 3-6 decades, prevalence of hypertension has increased by almost 30 times among urban dwellers and by about 10 times among rural inhabitants (5). Although hypertension prevalence is generally lower in rural Indian population in comparison to urban but there has been steady increase of hypertension overtime in the rural population as well (6)

Various factors might have contributed to this rising trend like changing life style, environment, diet, stress, industrialization and urbanization etc. The prevalence rate of hypertension also varies widely in rural India because of different social, economical and cultural background. 


\section{Aims \& Objectives}

1. To assess the prevalence of hypertension

2. To find out correlates of hypertension among the adults in rural population of Meerut

\section{Material \& Methods}

Study Type \& study area: It was a community based cross-sectional study. This study was conducted at village Khajuri in Kila Parikshitgarh block, Meerut.

Study Population: All the adults aged $\geq 18$ years residing in the study area.

sample size Sample size was calculated by taking pooled prevalence in rural areas of north India as $14.5 \%$ (7) at $95 \%$ level of confidence and $6 \%$ absolute allowable error. It came out as 138 \& final sample size worked out was 150 .

Data collection: Data was collected, after taking informed written consent from the participants, using a pre-designed pre-tested structured schedule. For gathering the data a personal door to door visit was made to each household, selected using systematic random sampling technique. Sampling unit was a house hold and one individual $\geq 18$ years of age from each household was selected randomly by lottery method. If no adult aged $\geq$ 18 years was found in a family or the selected house was found locked at the time of interview then adjacent house was visited.

Inclusion Criteria: Individuals who had completed 18 years of age at the time of data collection from the selected households

Exclusion Criteria: Subjects $<18$ years of age, who didn't give the consent, who were not found well oriented, residing in the area for $<6$ months, pregnant females, severely ill and bed ridden persons were excluded from the study.

Working Definition: Overweight and Obesity was defined as body mass index (BMI) $\geq 23 \mathrm{~kg} / \mathrm{m} 2$ and $\mathrm{BMI}$ $\geq 27.5 \mathrm{~kg} / \mathrm{m} 2$ respectively (8). Waist Hip Ratio of $>0.95$ for males and $>0.85$ for females was considered to indicate abdominal obesity.(9) Waist circumference of $\geq 100 \mathrm{~cm}$ for males and $\geq 90 \mathrm{~cm}$ for females was considered as truncal obesity.(9) Two consecutive readings was made for each site to the nearest $0.5 \mathrm{~cm}$ using a non-stretchable fiber measuring tape on a horizontal plane without compression of skin. Participants with IDRS value of $<30$ were categorized as low risk, those with values between 30 and 50 as medium risk and those with score $\geq 60$ as high risk for diabetes (10)

For hypertension JNC-VII criteria was used. A person was considered hypertensive if Systolic BP $\geq 140 \mathrm{mmHg}$ and/or diastolic BP $\geq 90 \mathrm{mmHg}$ or subject was currently taking anti-hypertensive treatment. Average of two BP readings taken at an interval of 5 minutes was calculated and finally recorded. All the subjects detected as hypertensive were referred to rural health and training center, Khajuri for further workup.
Ethical Approval: Ethical approval was taken from institutional ethical committee of Subharti Medical College, Meerut.

Statistical analysis: Data was analyzed using SPSS version19.Categorical variables were expressed in frequency and percentages. Association between the variables were analyzed by applying chi-square $\&$ fisher exact test

\section{Results}

(Table 1) In present study, the prevalence of hypertension came out to be $33.3 \%$ among the study subjects. Majority of participants had either no or mild stress while only $18.7 \%$ participants were having high stress. $26.7 \%$ participants were having very high IDRS and very few were having low IDRS. According to BMI, 24.7\% participants were overweight and $22.0 \%$ were obese. Truncal obesity was present only in $27.3 \%$ of participants but $42.7 \%$ participants were having deranged WHR.

Table 2 shows socio demographic characteristics of nonhypertensive and hypertensive groups. The association of hypertension status was found to be statistically significant with increasing age, gender and education. There was no significant association found between hypertension and marital status, occupation, type of family and Socio Economic Status of the participants.

According to (Table 3), there was increase in the prevalence of hypertension with increase in stress level, but this association between stress level and hypertension status was not found to be significant. Increasing trend of hypertension was also seen with disturbed sleep and this association was found to be significant. Participants with low/moderate IDRS had less hypertension when compared with participants with high IDRS. There was a significant association seen between hypertension status and IDRS. Similarly, participants having normal BMI were less hypertensive as compared to participants who were overweight or obese. There was a significant association seen between BMI and hypertension status. Participants with normal WHR had less hypertension when compared with participants with deranged WHR, there was a significant association seen between hypertension status and WHR. Association between truncal obesity and hypertension status was also found to be significant.

\section{Discussion}

The prevalence of hypertension in our study came out to be $33.3 \%$. In a systematic review on hypertension, in India overall prevalence of hypertension came out to be $29.8 \%$ while prevalence for hypertension in rural parts was $27.6 \%$. Regional estimates for prevalence of hypertension in rural north-India was $14.4 \%$. (7) Clearly prevalence in our study was closer to overall prevalence of hypertension in India rather than to rural north. This difference could be due to the fact that in Meerut villages are more developed when compared to other rural areas of north India. 
Association of hypertension status was found to be statistically significant with age and gender. Other studies also showed significant association of prevalence of hypertension with age and gender. $(6,7,11)$ It is clear that with increasing age progressive rise of blood pressure is seen.

There was a clear-cut increase in a prevalence of hypertension with increase in stress level, but this association between stress level and hypertension status was not found to be significant. There are not many studies regarding association of subjective stress with hypertension in India but some indirect links can be found. A review article by R. Gupta also states that psychosocial stress is an important environmental factor in hypertension. (6) Increasing trend of hypertension was also seen with disturbed sleep and this association between disturbed sleep and hypertension status was found to be significant. Participants with low/moderate IDRS had less hypertension when compared with participants with high IDRS. There was a significant association seen between hypertension status and IDRS. Studies by M Singh(12) and by S. Yadav et al(13) also show that subjects with glucose intolerance have greater risk of hypertension.

In our study there was a significant association seen between BMI and hypertension status. Participants with normal WHR had less hypertension when compared with participants with deranged WHR, there was a significant association seen between hypertension status and WHR. Association between truncal obesity and hypertension status was also found to be significant. This was in accordance with study by M Singh (12), by S Das et al (11), by S. Yadav et al (13), and by J Kishore et al (14)

\section{Conclusion}

In the present study prevalence of hypertension came out to be $33.3 \%$. Association of hypertension status came out to be highly significant with age and gender. Association between disturbed sleep, IDRS, BMI, WHR and truncal obesity was also found to be statistically significant with hypertension status.

\section{Recommendation}

The observed prevalence of hypertension in this study (and other studies as well) suggest strong need of nationwide policies towards prevention and control of hypertension in India. These policies could include health education, life style changes, stress management and control of insulin resistance etc.

\section{Limitation of the study}

This study was conducted in smaller sample size so study with larger sample is needed to generalize the results and any causal association cannot be derived from the present cross-sectional study design. Participants were labelled as hypertensive by single day blood pressure reading only.

\section{Relevance of the study}

This study highlights the need of awareness generation about hypertension, life style changes and stress management.

\section{Authors Contribution}

MG: Contributed in all the process of study. RB \& MG: Involved in all the process of study. CKG: Involved in data analysis, manuscript editing.

\section{References}

1. World Health Organization.health topics. Online Q\&As on hypertension. updated Sep2015. available from: URL: http://www.who.int/features/qa/82/en/

Accessed on 27th December, 2018.

2. Nissien A. Bothig $S$, Grenroth 11, Lopez AD. Hypertension in developing countries. World Health Stat Q. 1988; 41: 141-154.

3. Reddy KS. Hypertension control in developing countries: generic issues. J Hum Hypertension. 1996; 10:S33-38.

4. Hypertension study group. Prevalence, awareness, treatment and control of hypertension among the elderly in Bangladesh and India: a multicentre study. Bull World Health Organ. 2001; 79: 490-500.

5. Gupta R. Meta analysis of prevalence of hypertension in India. Ind Heart Journal 1997; 49: 43-48. [PubMed]

6. R Gupta. Trend in hypertension epidemiology in India. J Hum Hypertens. 2004: 73- 78. DOI: 10.1038/sj.jhh.1001633 (PubMed)

7. A Raghupathy et al. Hypertension in India: a systematic review and meta-analysis of prevalence, awareness, and control of hypertension. J of Hypertens. 2014 June: 32(6): 1170-76. PMID: 24621804

8. WHO expert consultation. Appropriate body-mass index for Asian populations and its implications for policy and intervention strategies. The Lancet 2004 Jan; 363: 157-163

9. Gupta R, Sharma KK, Gupta A et al. Persistent High Prevalence of Cardiovascular Risk Factors in the Urban Middle Class in India: Jaipur Heart Watch-5. JAPI 2012 Mar;60:11-16. [PubMed]

10. Mohan V, Anbalagan V P. Expanding role of the Madras Diabetes Research Foundation - Indian Diabetes Risk Score in clinical practice. Ind J of Endocrin Metabol. 2013 Jan-Feb; 17 (1): 31-36.

11. S Das, K Sanyal, A Basu. Study of urban community- survey in India: growing trend of high prevalence of hypertension in a developing country. Int. J. Med. Sci: 2005:70-78. doi: $10.7150 /$ ijms.2.70,PMID: 15968343

12. Singh, M., Kotwal, A., Mittal, C. et al. Prevalence and correlates of hypertension in a semi-rural population of Southern India. J Hum Hypertens 32, 66-74 (2018).

https://doi.org/10.1038/s41371-017-0010-5S PMID: 29180803

13. Yadav, R Boddula, G Genitta, $V$ Bhatia, $S$ Kongara, S Julka et al. Prevalence and risk factors of pre-hypertension and hypertension in an affluent north Indian population. Indian J Med Res. 2008 Dec;128:712-720

14. Kishore J, Gupta N., Kohli C, Kumar N. Prevalence of Hypertension and Determination of Its Risk Factors in Rural Delhi. Inter J Hypertens. Vol 2016, Article ID 7962595, 6 pages http://dx.doi.org/10.1155/2016/7962595 


\section{Tables}

TABLE 1 DISTRIBUTION OF HYPERTENSION STATUS, STRESS LEVEL, INDIAN DIABETES RISK SCORE AND OBESITY AMONG THE PARTICIPANTS

\begin{tabular}{|c|c|c|c|}
\hline Variable & Group & Frequency & Percentage(\%) \\
\hline \multirow[t]{2}{*}{ Hypertension Status } & Non-Hypertensive & 100 & $66.7 \%$ \\
\hline & Hypertensive & 50 & $33.3 \%$ \\
\hline \multirow[t]{3}{*}{ Stress Level } & Normal & 21 & $14 \%$ \\
\hline & Mildly Stressed & 101 & $67.3 \%$ \\
\hline & Highly Stressed & 28 & $18.7 \%$ \\
\hline \multirow[t]{3}{*}{ IDRS (Indian Diabetes Risk Score) } & Low Risk & 9 & $6.0 \%$ \\
\hline & Moderate Risk & 101 & $67.3 \%$ \\
\hline & Very High Risk & 40 & $26.7 \%$ \\
\hline \multirow[t]{4}{*}{ BMI Cut- Off } & Underweight & 24 & $16 \%$ \\
\hline & Normal Weight & 56 & $37.3 \%$ \\
\hline & Overweight & 37 & $24.7 \%$ \\
\hline & Obese & 33 & $22 \%$ \\
\hline \multirow[t]{2}{*}{ Truncal Obesity } & Absent & 109 & $72.7 \%$ \\
\hline & Present & 41 & $27.3 \%$ \\
\hline \multirow[t]{2}{*}{ Waist Hip Ratio } & Normal & 86 & $57.3 \%$ \\
\hline & Deranged & 64 & $42.7 \%$ \\
\hline \multicolumn{2}{|l|}{ Total } & 150 & $100 \%$ \\
\hline
\end{tabular}

\begin{tabular}{|c|c|c|c|c|c|c|c|c|}
\hline \multirow[t]{3}{*}{ Variable } & \multirow[t]{3}{*}{ Group } & \multicolumn{7}{|c|}{ Hypertensive status } \\
\hline & & \multicolumn{2}{|c|}{ Non-Hypertensive } & \multicolumn{2}{|c|}{ Hypertensive } & \multicolumn{2}{|c|}{ Total } & \multirow[t]{2}{*}{$P$ value } \\
\hline & & No. & $\%$ & No. & $\%$ & No. & $\%$ & \\
\hline \multirow[t]{4}{*}{ Age } & $<40$ years & 70 & $84.3 \%$ & 13 & $15.7 \%$ & 83 & $100 \%$ & \multirow[t]{4}{*}{$<0.001$} \\
\hline & $41-50$ years & 9 & $56.3 \%$ & 7 & $43.8 \%$ & 16 & $100 \%$ & \\
\hline & $51-60$ years & 18 & $60.0 \%$ & 12 & $40.0 \%$ & 30 & $100 \%$ & \\
\hline & $>60$ years & 3 & $14.3 \%$ & 18 & $85.7 \%$ & 21 & $100 \%$ & \\
\hline \multirow[t]{2}{*}{ Gender } & Male & 51 & $75.0 \%$ & 17 & $25.0 \%$ & 68 & $100 \%$ & \multirow[t]{2}{*}{0.049} \\
\hline & Female & 49 & $59.8 \%$ & 33 & $40.2 \%$ & 82 & $100 \%$ & \\
\hline \multirow[t]{2}{*}{ Religion } & Hindu & 24 & $61.5 \%$ & 15 & $38.5 \%$ & 39 & $100 \%$ & \multirow[t]{2}{*}{0.430} \\
\hline & Muslim & 76 & $68.5 \%$ & 35 & $31.5 \%$ & 111 & $100 \%$ & \\
\hline \multirow[t]{2}{*}{ Marital status } & Married & 82 & $67.2 \%$ & 40 & $32.8 \%$ & 122 & $100 \%$ & \multirow[t]{2}{*}{0.767} \\
\hline & Unmarried/widow & 18 & $64.3 \%$ & 10 & $35.7 \%$ & 28 & $100 \%$ & \\
\hline \multirow[t]{3}{*}{ Education } & Illiterate / just literate & 27 & $46.6 \%$ & 31 & $53.4 \%$ & 58 & $100 \%$ & \multirow[t]{3}{*}{$<0.001$} \\
\hline & Primary/middle school & 23 & $76.7 \%$ & 7 & $23.3 \%$ & 30 & $100 \%$ & \\
\hline & High school or above & 50 & 80.6 & 12 & $19.4 \%$ & 62 & $100 \%$ & \\
\hline \multirow[t]{4}{*}{ Occupation } & Unemployed & 6 & $42.9 \%$ & 8 & $57.1 \%$ & 14 & $100 \%$ & \multirow[t]{4}{*}{0.117} \\
\hline & Farmer/agriculture & 31 & $73.8 \%$ & 11 & $26.2 \%$ & 42 & $100 \%$ & \\
\hline & Service /business & 12 & $80.0 \%$ & 3 & $20.0 \%$ & 15 & $100 \%$ & \\
\hline & Housewife/student & 51 & $64.6 \%$ & 28 & $35.4 \%$ & 79 & $100 \%$ & \\
\hline \multirow[t]{2}{*}{ Type of family } & Nuclear family & 21 & $70.0 \%$ & 9 & $30.0 \%$ & 30 & $100 \%$ & \multirow[t]{2}{*}{0.665} \\
\hline & Joint family & 79 & $65.8 \%$ & 41 & $34.2 \%$ & 120 & $100 \%$ & \\
\hline \multirow{3}{*}{$\begin{array}{c}\text { Socio economic } \\
\text { status }\end{array}$} & SES class I/II & 35 & $59.3 \%$ & 24 & $40.7 \%$ & 59 & $100 \%$ & \multirow[t]{3}{*}{0.229} \\
\hline & SES class III & 31 & $75.6 \%$ & 10 & $24.4 \%$ & 41 & $100 \%$ & \\
\hline & SES class IV/V & 34 & $68.0 \%$ & 16 & $32.0 \%$ & 50 & $100 \%$ & \\
\hline \multicolumn{2}{|r|}{ Total } & 100 & $66.7 \%$ & 50 & $33.3 \%$ & 150 & $100 \%$ & \\
\hline
\end{tabular}


TABLE 3 ASSOCIATION OF HYPERTENSION WITH STRESS LEVEL, DISTURBED SLEEP, INDIAN DIABETES RISK SCORE AND OBESITY

\begin{tabular}{|c|c|c|c|c|c|c|c|c|}
\hline \multirow[t]{3}{*}{ Variable } & \multirow[t]{3}{*}{ Group } & \multicolumn{7}{|c|}{ Hypertensive status } \\
\hline & & \multicolumn{2}{|c|}{ Non-Hypertensive } & \multicolumn{2}{|c|}{ Hypertensive } & \multicolumn{2}{|l|}{ Total } & \multirow[t]{2}{*}{$p$ value } \\
\hline & & No. & $\%$ & No. & $\%$ & No. & $\%$ & \\
\hline \multirow[t]{3}{*}{ Stress Level } & Normal & 16 & $76.2 \%$ & 5 & $23.8 \%$ & 21 & $100 \%$ & \multirow[t]{3}{*}{0.208} \\
\hline & Stressed & 69 & $68.3 \%$ & 32 & $31.7 \%$ & 101 & $100 \%$ & \\
\hline & Highly Stressed & 15 & $53.6 \%$ & 13 & $46.4 \%$ & 28 & $100 \%$ & \\
\hline \multirow[t]{3}{*}{ Disturbed sleep } & Never & 59 & $74.7 \%$ & 20 & $25.3 \%$ & 79 & $100 \%$ & \multirow[t]{3}{*}{0.030} \\
\hline & Sometimes & 31 & $63.3 \%$ & 18 & $36.7 \%$ & 49 & $100 \%$ & \\
\hline & Often/ always & 10 & $45.5 \%$ & 12 & $54.5 \%$ & 22 & $100 \%$ & \\
\hline \multirow[t]{2}{*}{ IDRS } & Low Risk / Moderate Risk & 83 & $75.5 \%$ & 27 & $24.5 \%$ & 110 & $100 \%$ & \multirow[t]{2}{*}{$<0.001$} \\
\hline & Very high risk & 17 & $42.5 \%$ & 23 & $57.5 \%$ & 40 & $100 \%$ & \\
\hline \multirow[t]{3}{*}{ BMI Cut- Off } & Normal Weight & 58 & $72.5 \%$ & 22 & $27.5 \%$ & 80 & $100 \%$ & \multirow[t]{3}{*}{0.034} \\
\hline & Overweight & 24 & $64.9 \%$ & 13 & $35.1 \%$ & 37 & $100 \%$ & \\
\hline & Obese & 18 & $54.5 \%$ & 15 & $45.5 \%$ & 33 & $100 \%$ & \\
\hline \multirow[t]{2}{*}{ Waist Hip Ratio } & Normal & 66 & $76.7 \%$ & $20-$ & $23.3 \%$ & 86 & $100 \%$ & \multirow[t]{2}{*}{0.002} \\
\hline & Deranged & 34 & $53.1 \%$ & 30 & $46.9 \%$ & 64 & $100 \%$ & \\
\hline \multirow[t]{2}{*}{ Truncal Obesity } & Absent & 83 & $76.1 \%$ & 26 & $23.9 \%$ & 109 & $100 \%$ & \multirow[t]{2}{*}{$<0.001$} \\
\hline & Present & 17 & $41.5 \%$ & 24 & $58.5 \%$ & 41 & $100 \%$ & \\
\hline & Total & 100 & $66.7 \%$ & 50 & $33.3 \%$ & 150 & $100 \%$ & \\
\hline
\end{tabular}

